\title{
Development of Vernonia amygdalina Leaf Extract Emulsion Formulations in Controlling Gray Mold Disease on Tomato (Lycopersicon esculentum Mill.)
}

\author{
Siti Fairuz Yusoff ${ }^{1,2}$, Farah Farhanah Haron ${ }^{3}$, Norhayu Asib ${ }^{1}{ }^{\circledR}$, Mahmud Tengku Muda Mohamed ${ }^{4}$ \\ and Siti Izera Ismail ${ }^{1, *(D)}$ \\ 1 Department of Plant Protection, Faculty of Agriculture, Universiti Putra Malaysia, Serdang, \\ Selangor 43400, Malaysia; yuezyusoff@gmail.com (S.F.Y.); norhayuasib@upm.edu.my (N.A.) \\ 2 Agricultural Science Department, Faculty of Technical and Vocational, Universiti Pendidikan Sultan Idris, \\ Tanjong Malim, Perak 35900, Malaysia \\ 3 Horticulture Research Centre, Pest and Disease Management Programme, Malaysian Agricultural Research \\ and Development Institute, Serdang, Selangor 43400, Malaysia; farahfarhanah@mardi.gov \\ 4 Department of Crop Science, Faculty of Agriculture, Universiti Putra Malaysia, Serdang, \\ Selangor 43400, Malaysia; mtmm@upm.edu.my \\ * Correspondence: izera@upm.edu.my; Tel.: +603-97694851
}

Citation: Yusoff, S.F.; Haron, F.F.; Asib, N.; Mohamed, M.T.M.; Ismail, S.I. Development of Vernonia amygdalina Leaf Extract Emulsion Formulations in Controlling Gray Mold Disease on Tomato (Lycopersicon esculentum Mill.). Agronomy 2021, 11, 373. https://doi.org/10.3390/ agronomy 11020373

Academic Editors:

Sanghamitra Majumdar and Luca Pagano

Received: 23 December 2020

Accepted: 16 February 2021

Published: 20 February 2021

Publisher's Note: MDPI stays neutral with regard to jurisdictional claims in published maps and institutional affiliations.

Copyright: (c) 2021 by the authors. Licensee MDPI, Basel, Switzerland. This article is an open access article distributed under the terms and conditions of the Creative Commons Attribution (CC BY) license (https:// creativecommons.org/licenses/by/ $4.0 /)$.

\begin{abstract}
Postharvest fruits including tomatoes are commonly infected by gray mold disease resulting in significant economic losses in the fruit industry. Therefore, this study aimed to develop botanical fungicide derived from Vernonia amygdalina leaf extract to control gray mold on tomato. The emulsion formulation containing surfactant, oil carrier and water was optimized at different non-ionic alkyl polyglucoside surfactants through eleven combinations of oil to surfactant ratio $(0: 10,1: 9,2: 8,3: 7,4: 6$, 5:5, 6:4, 7:3, 8:2, 9:1 and 10:0 $w / w)$. From eight selected formulations, two formulations, F5 and F7 showed stable in storage, remarkable thermodynamic stability, smaller particle size (66.44 and 139.63 $\mathrm{nm})$, highly stable in zeta potential $(-32.70$ and $-31.70 \mathrm{mV})$, low in polydispersity index $(0.41$ and $0.40 \mathrm{PdI})$, low in viscosity $(4.20$ and $4.37 \mathrm{cP})$ and low in surface tension $(27.62$ and $26.41 \mathrm{mN} / \mathrm{m})$ as compared to other formulations. In situ antifungal activity on tomato fruits showed F5 formulation had a fungicidal activity against $B$. cinerea with zero disease incidence and severity, whereas F7 formulation reduced $62.5 \%$ disease incidence compared to a positive control with scale 1 . Based on these findings, F5 formulation exhibited pronounced antifungal activity and may contribute to the development of new and safe antifungal product against gray mold on tomato.
\end{abstract}

Keywords: Vernonia amygdalina; antifungal activity; Botrytis cinerea; nanoemulsion formulation; gray mold disease; particle size; zeta potential; polydispersity index; viscosity; tomato

\section{Introduction}

Botrytis cinerea has attracted more attention, especially in plant disease management, because of its broad host range and establishment in temperate and tropical regions [1]. Tomato is a susceptible host for B. cinerea, and its prevalence causes gray mold disease, resulting in huge economic losses [2]. New strategies and research are ongoing to develop reliable, ecofriendly and low-toxicity fungicide to control this disastrous pathogen.

Plants develop several secondary metabolic pathways that generate numerous novel substances as a natural defense against biotic and abiotic stresses, including pathogen invasion. Botanicals with antifungal compounds can be exploited for plant disease management $[1,3]$. Active ingredients from botanical extracts commonly comprise high-volatility and lipophilic compounds that are easily degraded and lost by polymerization and oxidation processes $[4,5]$. To overcome this obstacle, researchers have suggested the use of the active ingredient in the formulation form to preserve their stability and efficiency. Generally, active ingredients from natural sources have low toxicity and biodegradability and perform 
various modes of action against targeted pathogen [6-8]. Botanical formulations have a few types, such as emulsion, controlled release, tablet and dust powder formulation [9]. Among these formulations, emulsion formulation is preferred by researchers for the crude extract to optimize the solubility of bioactive compounds because they exist in various classes of secondary metabolites [10].

Recently, nanotechnology has been adapted in botanical formulations in sustainable agriculture [11]. Nanoemulsion formulation is emerging nanotechnology in the agriculture sector. This process is thermodynamically stable, has high kinetics, involves nanoparticle transport, facilitates ease in diffusion, and has high solubilization capacity [4]. In addition, it could offer maximum efficacy, provide high surface coverage property of targeted pathogen, low dosage of the active agent and durability [12]. The particle size of the nanoemulsion is usually less than $500 \mathrm{~nm}$, and the size distribution does not change even upon dilution with water $[13,14]$. However, Ostwald ripening is a major issue in nanoemulsion development. Oswald ripening happens when small droplets diffuse through the continuous phase toward large drops and when the average droplet size increases [15]. Thus, to establish the effective nanoemulsion formulation, Kale and Deore [16] recommended the evaluation of the formulation in terms of visual appearance, viscosity, $\mathrm{pH}$, zeta potential analysis, phase behavior, polydispersity and stability test.

Vernonia amygdalina extract contains antifungal substances, including squalene, phytol, triacontane, heptacosane and neophytadiene [17]. Advances in the nanoemulsion formulation in the pesticide industry strengthen the interest in the formulation development of $V$. amygdalina leaf extract as a biofungicide against tomato gray mold disease in safe and efficient ways. Biofungicide formulation has not been developed using $V$. amygdalina leaf extract. Hence, this study was executed to develop the emulsion formulation of $V$. amygdalina leaf extract and their effectiveness against gray mold disease of tomato.

\section{Materials and Methods}

\subsection{Plant Material}

V. amygdalina was obtained from Ladang 15, Universiti Putra Malaysia, Serdang, Malaysia. The matured leaves were harvested and immediately transported to the Postharvest Laboratory, Faculty of Agriculture, Universiti Putra Malaysia. The harvested leaves were washed thoroughly, dried under shade for a week, and subsequently dried in the oven at $40{ }^{\circ} \mathrm{C}$ for $4 \mathrm{~h}$ [18]. The dried leaves were fine-ground using a high-speed grinder (Model HOF-500g-S1, Kuala Lumpur, Malaysia) for $2 \mathrm{~min}$. The fine-powdered leaves were placed in an airtight container prior to crude extraction.

\subsection{Preparation of V. amygdalina Crude Extract}

Sequential extraction was conducted as described by Haron et al. [19]. Sequential extraction was adopted to minimize analogous compounds. A total of $500 \mathrm{~g}$ powdered $V$. amygdalina leaves were macerated and extracted in $5 \mathrm{~L}$ of organic solvents consisting of hexane (Bendosen Laboratory Chemicals, Kuala Lumpur, Malaysia), dichloromethane (DCM, Macron-Fine Chemicals, Illkirch Cedex, France) or methanol (HmbG Chemicals, Hamburg, Germany) for $48 \mathrm{~h}$ at room temperature. Then, the extracts were filtered using filter paper, and the flow-through was concentrated in a rotary evaporator (Buchi Rotary Evaporator R100, coupled to Buchi Vacuum pump V100 and Buchi Water Bath B100, Flawil, Switzerland) until a sticky dark green crude was formed. However, only the DCM crude extract was selected for the antifungal active component in formulation development due to the highest antifungal activities based on our previous work [17]. This was supported by phytochemical characterization of this crude extract that has been performed using gas chromatography-mass spectrometry (GC-MS) analysis as described by Yusoff et al. [17].

\subsubsection{Materials for Formulation Components}

Four types of non-ionic alkyl polyglucoside surfactants (Agnique MBL530B, Agnique MBL510H Glucopon 225DK, and Glucopon 215UP) and one type of palm oil based-carrier 
dimethyl amide (Agnique AMD810) were used as inert components in the formulation development. Both these surfactants and carrier were purchased from Cognis ${ }^{\circledR}$ Oleochemical (M) Sdn. Bhd. Glucopon was obtained from the palm kernel oil and glucose-based. It is approved by Swedish Society for nature conservation and ecolabeled as a "Good environmental choice". Meanwhile, Agnique is also palm oil based and listed as a sustainable solvent by BTC specialty chemical distribution. Sustainable solvent has a lower environmental impact, low toxicity, sustainable sources and biodegradability. Formulation emulsions were prepared using ultrapure water at $18.2 \mathrm{M} \Omega . \mathrm{cm}$ (Elga Purelab Water Purification System, United Kingdom). In our previous study, DCM V. amygdalina leaf extract (DVLE) at 400 and $500 \mathrm{mg} / \mathrm{mL}$ exhibited the highest antifungal activities against $B$. cinerea [17]. However, there was no significant difference between both concentrations on these activities. Thus, a lower dosage at $400 \mathrm{mg} / \mathrm{mL}$ was selected as the active ingredient for the emulsion formulation development. Active ingredient was prepared by dissolving DVLE at $400 \mathrm{mg}$ in $1 \mathrm{~mL}$ of acetone $(w / v)$.

\subsubsection{Preparation of Emulsion by Ternary Phase Diagram}

Emulsion formulations were prepared at room temperature using an aqueous titration method as described by Choupanian et al. [20]. The oil-to-surfactant ratios were set to 0:10, $1: 9,2: 8,3: 7,4: 6,5: 5,6: 4,7: 3,8: 2,9: 1$ and 10:0 $(w / w)$. Each combination series were placed in a $10-\mathrm{mL}$ glass test tube with screwed cap. A total of $0.5 \mathrm{~g}$ of combination sample was weighed using an analytical balance (Model HR-250AZ, Tokyo, Japan). Ultrapure water (dispersed phase) was titrated in $10 \%$ increment into the oil and surfactant mixture (continuous phase) and homogenized using vortex (Model QL866, Zhejiang, China) for $1 \mathrm{~min}$. The transition of the phase behaviors, such as fluidity, homogeneity, optical clarity, and transparency, was observed and recorded. The phase domain of the mixtures, such as isotropic, biphasic or triphasic, was analyzed using Chemix software version 7.0 and presented in the ternary phase diagram. This triangular diagram consisted of the percentage ratio of oil, water, and surfactant components.

\subsection{Selection of Emulsion Formulation Composition from Ternary Phase Diagrams}

Eight points from the isotropic region (one-phase) in the ternary phase diagrams containing $\leq 30 \%$ surfactant were selected and incorporated with the DVLE for further characterization tests. These selected formulations denoted as F1, F2, F3, F4, F5, F6, F7 and F8 were subjected to centrifugation stability, thermostability test, particle-size distribution, zeta potential, polydispersity index, viscosity measurement and surface tension.

\subsection{Characterization of Emulsion Formulation}

\subsubsection{Centrifugation Test of Formulation}

The selected formulations were centrifuged at $3500 \mathrm{rpm}$ for $30 \mathrm{~min}$ and incubated at room temperature $\left(25 \pm 2{ }^{\circ} \mathrm{C}\right)$ for 4 weeks [21]. The formulations were observed for their physical appearance and phase separation after the incubation period.

\subsubsection{Storage Stability and Thermostability Test of Formulation}

Stability and thermostability tests were conducted based on the registration of biopesticide guidelines by the Department of Agriculture and the World Health Organization and Food Agricultural Organization [22,23]. Two sets of selected formulations (F1-F8) were centrifuged at $4000 \mathrm{rpm}$ for $10 \mathrm{~min}$. Each set of the formula was maintained at $25^{\circ} \mathrm{C}$ for 4 months and at $54^{\circ} \mathrm{C}$ for 14 days. The physical stability appearance of each formulation was visually observed.

\subsubsection{Particle Size and Zeta Potential Measurement}

The formulation samples were diluted in ultrapure water in a ratio of 1:10. Each diluted formulation was vortex mixed for $1 \mathrm{~min}$. The folded capillary cells (DTS1070) were rinsed using ethanol, followed by deionized water several times prior to use. Ap- 
proximately $1.2 \mathrm{~mL}$ of the sample was injected carefully into the folded capillary cell. Immediately, the capillary cell was located into the cell holder in a correct orientation. Both particle size and zeta potential of the formulations were determined using zeta sizer nano series (Malvern Nano ZS, Worcestershire, UK) instrument that was preheated for half an hour before usage. The droplet size of the formulation was captured through the Brownian motion of the dispersed phase by using dynamic light scattering, and the zeta potential was measured via laser Doppler electrophoresis. The analysis was repeated thrice for each sample.

\subsubsection{Surface Tension Analysis}

The surface tension of each selected formulation was measured using an automatic surface tensiometer (Model BZY-102, Anhui, China) through the du Nouy ring method. Distilled water was used for calibration with a surface tension of $71.66 \mathrm{mN} / \mathrm{m}$. The platinum ring was dipped into acetone and flamed at an angle of $45^{\circ}$ for $1 \mathrm{~min}$ by using a spirit lamp. Next, the ring was washed using running distilled water and placed in the flamed for $20 \mathrm{~s}$. This precaution was carried out to avoid any contaminants from previous use that may affect the actual reading.

\subsubsection{Viscosity Analysis}

The viscosity of the formulations was determined using a digital viscometer (Model NDJ-5S, China) at ambient temperature. The spindle number of " 0 " was chosen in this analysis for the viscosity range of $10-100 \mathrm{mPa} . \mathrm{S}$ or cP. Exactly $25 \mathrm{~mL}$ of each selected formulation that was freshly prepared was loaded into a testing tube and fixed to the rotating sleeve. The formulation samples were kept at $25^{\circ} \mathrm{C}$. The rotation speed was set to $60 \mathrm{rpm}$, and the percentage rates were maintained within $43-76 \%$ to ensure reading accuracy. Each test was carried out thrice.

\subsection{In Situ Antifungal Activity of the Selected Nanoemulsion Formulations on Artificial Inoculated Tomato Fruits}

2.5.1. Tomato Fruit Preparation and Treatment Application

Tomato fruit variety Syngenta 1039 was obtained from Weng Seng Vegetable Products Sdn. Bhd. Cameron Highland, Pahang and transported to the Post-harvest Laboratory, Department of Crop Science, Faculty of Agriculture, Universiti Putra Malaysia. Healthy fruits and at maturity index 3 (green with slight red) according to the Malaysian Standard (MS 893:2010) were sorted carefully. A total of 480 sorted fruits were washed under running tap water and air-dried on the paper towel for $2 \mathrm{~h}$. Then, the fruits were surface-sterilized in $70 \%$ ethanol, rinsed with sterile distilled water, and then air-dried in laminar flow at ambient temperature for $30 \mathrm{~min}$. Next, 120 fruits were dipped into F5 and F7 formulations for $5 \mathrm{~min}$ with ten times formulation dilution. For negative control, 120 fruits were dipped in sterile distilled water. Exactly 120 other tomato fruits were dipped in $0.5 \mathrm{~g} / \mathrm{L}$ Kenlate fungicide solution (active ingredient: 50\% $w / w$ benomyl) and used as a positive control.

\subsubsection{Inoculation of B. cinerea on the Treated Tomato Fruit}

All treated fruits were excised using a sterile cork borer ( $2 \mathrm{~mm}$ deep and $5 \mathrm{~mm}$ wide) at the equatorial side. Mycelial plugs $(5 \mathrm{~mm}$ diameter) from the margins of potato dextrose agar (PDA) cultures were placed on each wound on the fruits. Five fruits were placed in a polyethylene plastic $(18 \mathrm{~cm} \times 26 \mathrm{~cm})$ with $0.05 \mathrm{~mm}$ thickness and 18 ventilation holes with a diameter size of $0.5 \mathrm{~cm}$. Each plastic package was sealed using a bag neck sealer tape and kept in a commercial export corrugated fiberboard, CFB $(30 \mathrm{~cm} \times 25 \mathrm{~cm} \times 15 \mathrm{~cm})$. Each CFB box was loaded with 12 sealed plastic packages containing treated fruits (60 fruits/box) and stored under ambient temperature for 12 days. Three replicates were employed for each treatment with 10 fruits/replication, and the experiment was repeated twice. After 
storage duration (day 12), disease incidence and disease severity index were determined using the following equations:

$$
\begin{gathered}
\text { Disease incidence }(\%)=\frac{\text { Number of infected fruits }}{\text { Total number of fruit per treatment }} \times 100 \\
D S I=\sum \frac{a \times n}{A B} \times 100
\end{gathered}
$$

where $a=$ disease scale, $n=$ number of fruits in a specific scale, $A=$ highest disease scale and $B=$ total number of fruits. The disease severity was evaluated based on a scale of $0-4$ on tomato fruits as described by [24] with some modifications (Table 1).

Table 1. Disease severity of gray mold disease on tomato fruit based on a specific scale.

\begin{tabular}{ccc}
\hline Severity Scale & Description & Inference \\
\hline 0 & $\begin{array}{c}\text { No visible symptoms of fruits } \\
1\end{array}$ & $\begin{array}{c}\text { No infection } \\
1-25 \% \text { inoculated area covered with slight necrotic } \\
26-50 \% \text { of inoculated area covered with necrotic } \\
\text { and white mycelia of fungal }\end{array}$ \\
3 & $\begin{array}{c}\text { Mild infection } \\
\text { mass appeared }\end{array}$ & Moderate infection \\
4 & $>76 \%$ necrotic tissue appears soft, watery & Severe infection \\
and decay & Very severe/devastating \\
\hline
\end{tabular}

\subsection{Statistical Analysis}

The treatments were arranged in a completely randomized design, and the data were subjected to analysis of variance. The means were separated using the Fisher's least significant difference (LSD) test at $p \leq 0.05$. Statistical analyses were carried out using SAS software (version 9.4).

\section{Results}

\subsection{Ternary Phase Diagrams of Emulsion Formulations}

The isotropic region is identified by optical observation after reaching equilibrium, and a phase diagram is constructed [25]. In this study, five ternary phase diagrams were generated to identify the isotropic region (one-phase) region of the emulsion system (Figures 1-5). Each diagram comprised three phase regions in the emulsion system. Among the constructed phase diagrams, the diagram shown in Figure 5 consists of Agnique MBL510, Agnique AMD810 and water, with the largest isotropic region of approximately $41 \%$. The phase diagram with equal ratios of Agnique MBL510 and Agnique MBL530 surfactant, Agnique AMD810 and water presented two isotropic regions (Figure 3). These two isotropic regions contributed $30 \%$ in this phase diagram and ranked as the second largest isotropic in this study. Figure 4 illustrates two isotropic regions with a total isotropic of 23\%. This combination of Agnique MBL530, Agnique AMD 810 and water system detected the smallest three-phase region at the ratio of $0-5 / 5-28 / 95-100$. The usage of Glucopon 225 and Glucopon 215 as the surfactant in the emulsion system depicted a similar pattern of one-phase, two-phase and three-phase regions with the isotropic region covering $12 \%$ of the phase diagram (Figures 1 and 2 ).

\subsection{Point of Selection}

Five ternary phase diagrams were thoroughly examined, and eight points were selected from their isotropic regions. The selected emulsion systems were labeled as F1, F2, F3, F4, F5, F6, F7 and F8. The selection composition ratios of F1-F8 are shown in Table 2. 


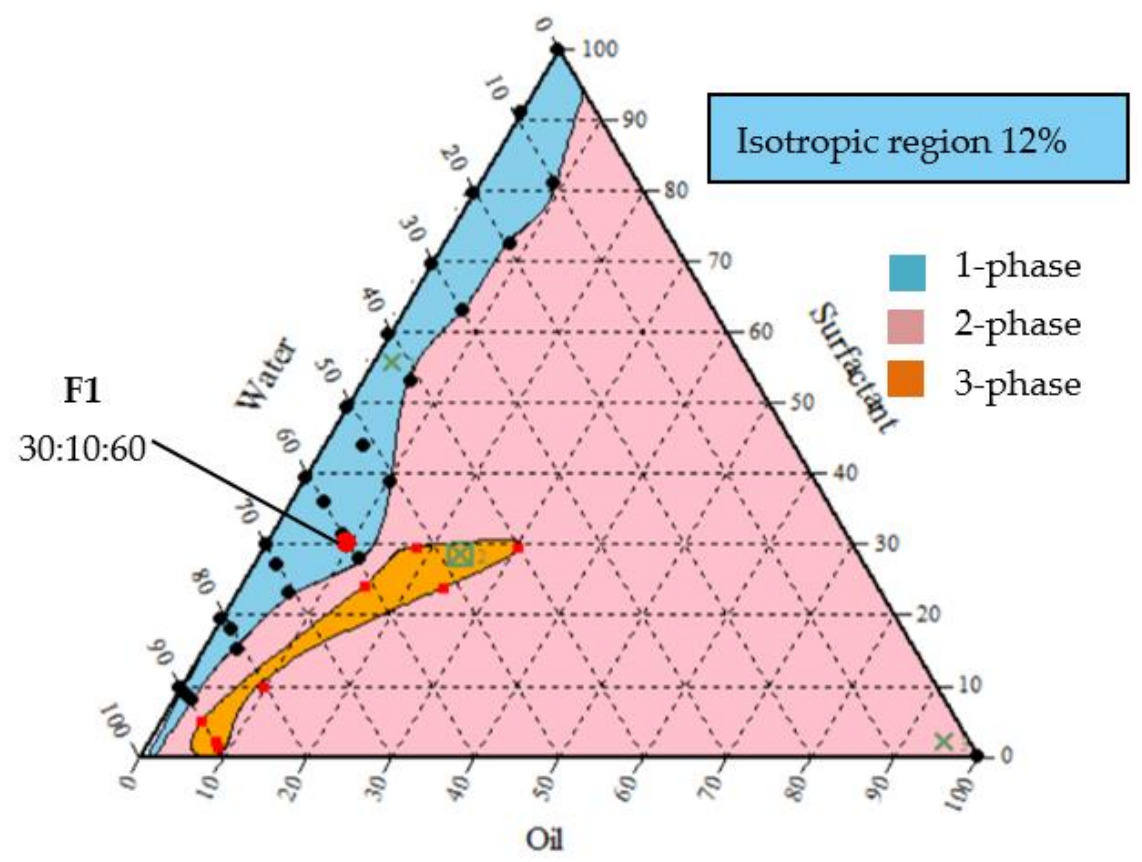

Figure 1. Phase diagram of Glucopon 225: AMD810: water system.

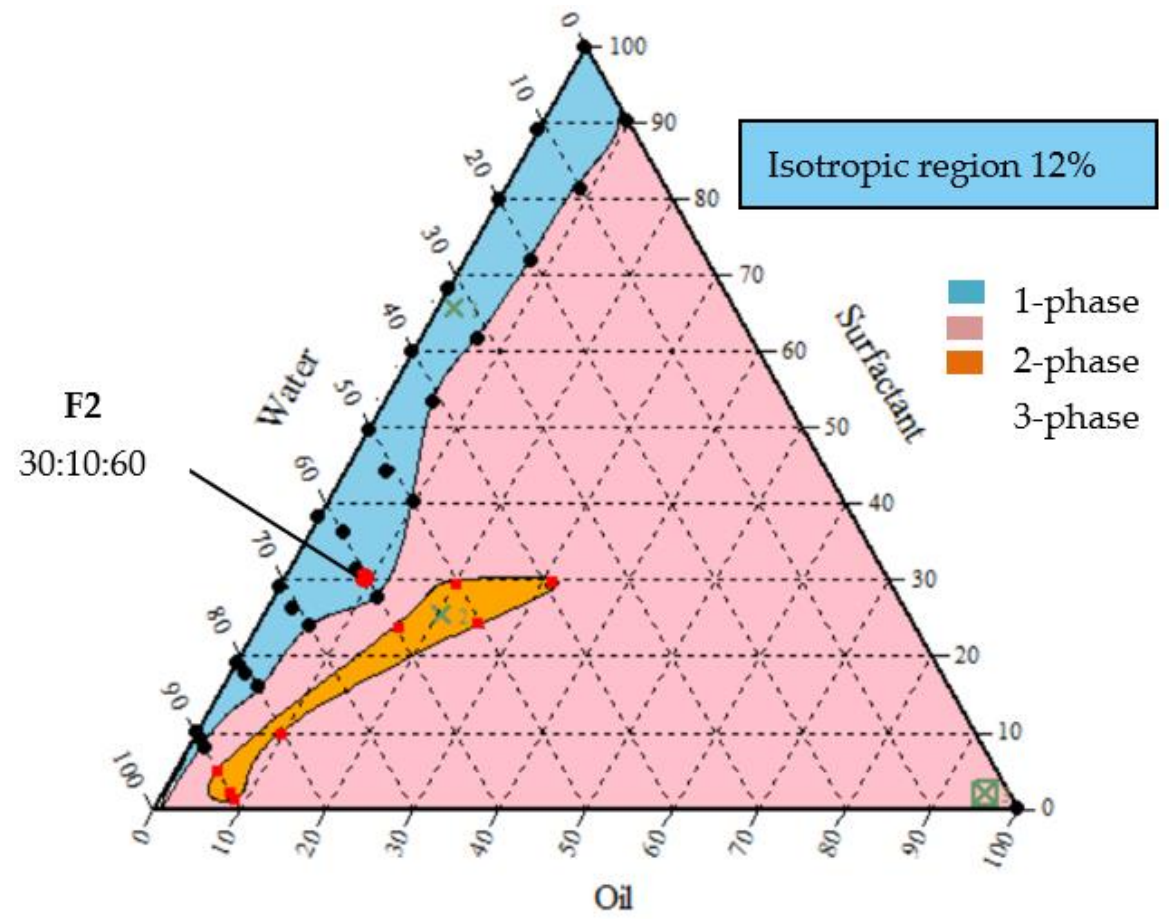

Figure 2. Phase diagram of Glucopon 215: Agnique AMD810: water system.

\subsection{Characterization of Emulsion Formulations}

The most important criterion for composition selection is the ability of the components to solubilize the active ingredient in the system. Table 3 presented the component composition ratio for eight emulsion formulations added with DVLE as the active ingredient. Each formulation was formulated in $60 \%$ of inert ingredients and $40 \%$ of DVLE. Overall, within the inert composition, the water component was the highest, whereas the oil carrier of Agnique AMD810 was the lowest component in the formulated emulsion, except for F6. These eight formulations with the DVLE were tested in terms of stability and physical quality characteristics. 


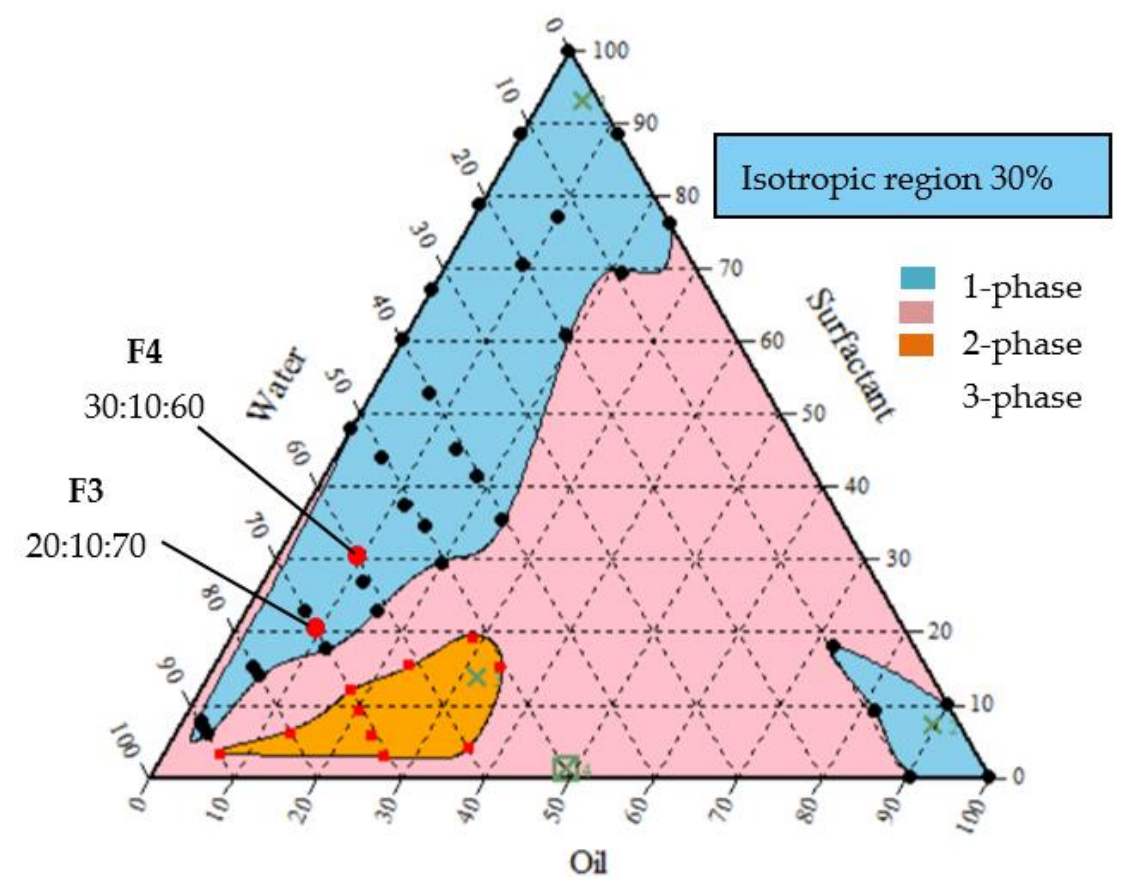

Figure 3. Phase diagram of 50\% Agnique MBL510 and Agnique 50\% MBL530: Agnique AMD810: water system.

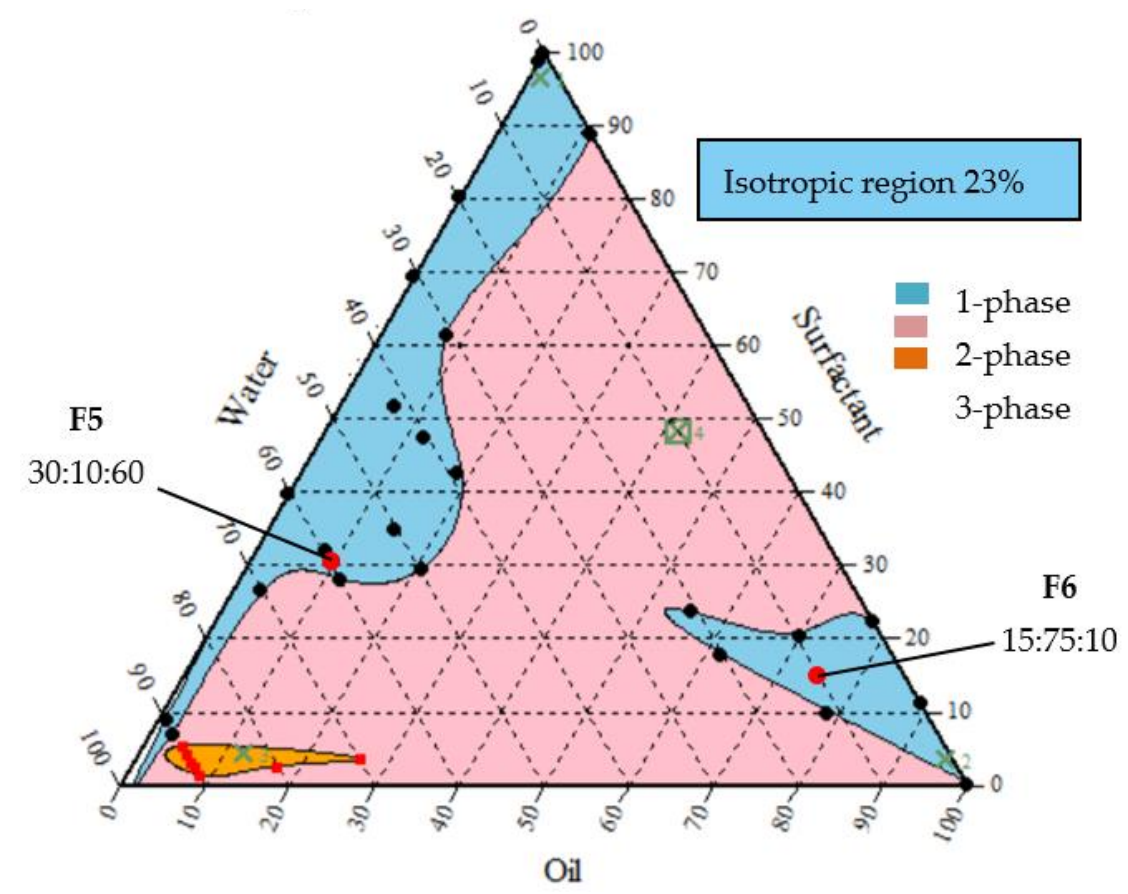

Figure 4. Phase diagram of Agnique MBL530: Agnique AMD810: water system.

3.4. Effects of Centrifugation, Storage Stability and Thermostability on Emulsion Formulation Homogeneity

All formulated emulsions remained in one-phase and were homogenous and stable without any phase separation after centrifugation and four months of storage at $25^{\circ} \mathrm{C}$. Based on the thermostability test at $54{ }^{\circ} \mathrm{C}$, only four emulsion formulations (F5, F6, F7 and F8) had consistent homogeneity and stability after two weeks of incubation. 


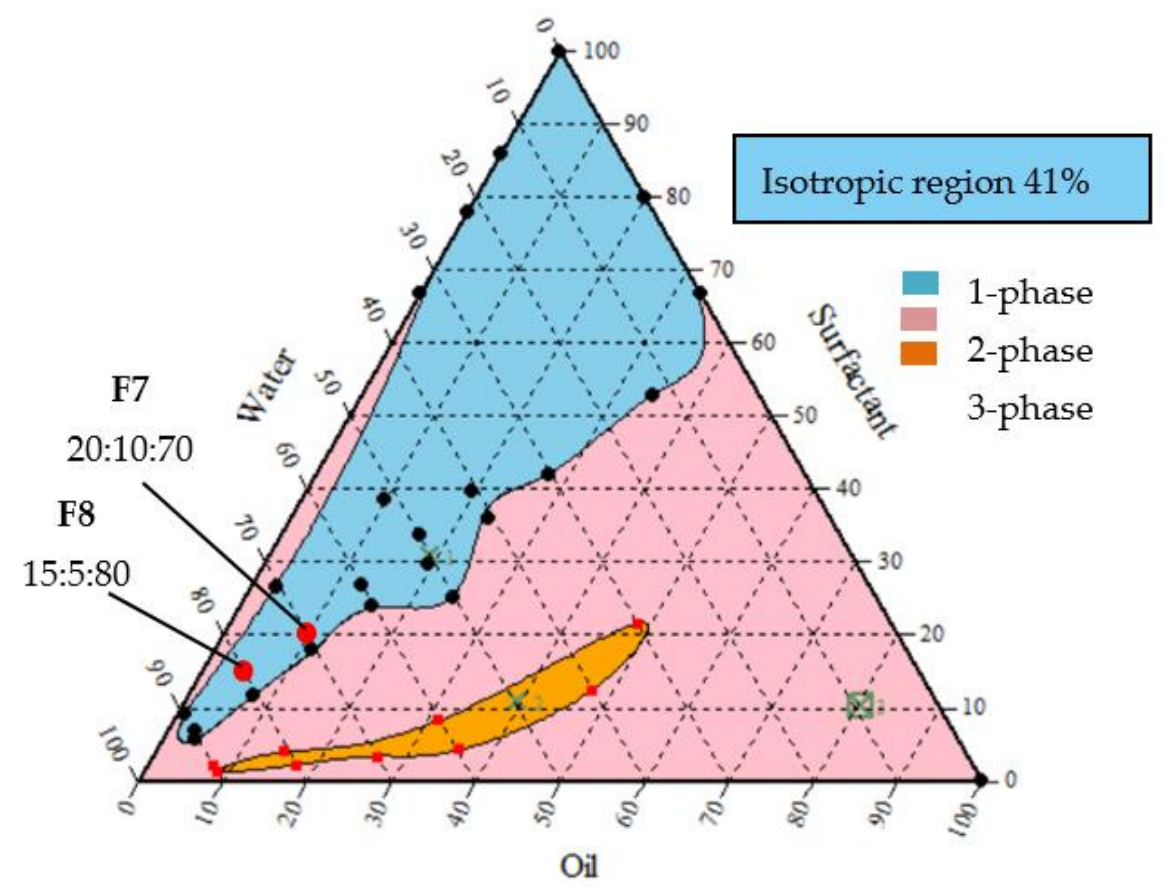

Figure 5. Phase diagram of Agnique MBL510: Agnique AMD810: water system.

Table 2. Selected points component composition without the active ingredient.

\begin{tabular}{cc}
\hline Formulation & Component Composition Ratio \\
\hline F1 & 30 Glucopon 225: 10 Agnique AMD810: 60 water \\
F2 & 30 Glucopon 215: 10 Agnique AMD810: 60 water \\
F3 & 20 mix Agnique MBL510 and MBL530: 10 Agnique AMD810: 70 water \\
F4 & 30 mix Agnique MBL510 and MBL530: 10 Agnique AMD810: 60 water \\
F5 & 30 Agnique MBL530: 10 Agnique AMD810: 60 water \\
F6 & 15 Agnique MBL530: 75 Agnique AMD810: 10 water \\
F7 & 20 Agnique MBL510: 10 Agnique AMD810: 70 water \\
F8 & 15 Agnique MBL510: 5 Agnique AMD810: 80 water \\
\hline
\end{tabular}

Table 3. Emulsion formulations composition with DVLE as the active ingredient.

\begin{tabular}{|c|c|c|c|c|c|c|c|c|}
\hline \multirow[b]{2}{*}{ Formulation } & \multicolumn{8}{|c|}{ Composition Ratio $(\% w / w)$} \\
\hline & Glucopon 225 & Glucopon 215 & Mix Agnique MBL510 + MBL530 & $\begin{array}{l}\text { Agnique } \\
\text { MBL530 }\end{array}$ & $\begin{array}{l}\text { Agnique } \\
\text { MBL510 }\end{array}$ & $\begin{array}{l}\text { Agnique } \\
\text { AMD810 }\end{array}$ & Water & DVLE \\
\hline F1 & 18 & - & - & - & - & 6 & 36 & 40 \\
\hline F2 & - & 18 & - & - & - & 6 & 36 & 40 \\
\hline F3 & - & - & 12 & - & - & 6 & 42 & 40 \\
\hline F4 & - & - & 18 & - & - & 6 & 36 & 40 \\
\hline F5 & - & - & - & 18 & - & 6 & 36 & 40 \\
\hline F6 & - & - & - & 9 & - & 45 & 6 & 40 \\
\hline F7 & - & - & - & - & 12 & 6 & 42 & 40 \\
\hline F8 & - & - & - & - & 9 & 3 & 48 & 40 \\
\hline
\end{tabular}

DVLE refers to DCM V. amygdalina leaf extract.

\subsection{Physical Characteristics of Emulsion Formulations}

Emulsion formulations containing active ingredient DVLE were physically characterized in terms of particle size, polydispersity index, viscosity, surface tension and zeta potential (Table 4). F5 and F8 showed the smallest particle size droplets. Meanwhile, F2 appeared as the largest particle droplet. F5 and F8 indicated smaller particle size than F7. However, both F5 and F8 were not significantly different at $p>0.05$. The polydispersity index (PdI) of all emulsion formulations varied from 0.07 to 0.81 . Among the emulsion formulations, F2 expressed the lowest PdI value, whereas F8 had the highest PdI reading. In terms of viscosity, F1, F2, F3, F5, F6 and F7 had low viscosity with the range of 4.20-4.68 
cP. The highest viscosity was obtained for F8. Overall, the surface tension of formulated emulsions was in the range of $25.62-29.85 \mathrm{mN} / \mathrm{m}$. The lowest surface tension among the formulations was recorded for F4, followed by F2, F7, F1, F3, F5, F6 and F8. However, the surface tension between F1 and F3 did not significantly differ. In relation to zeta potential, a higher zeta potential value of either positive or negative was recommended for stable emulsion formulation. The zeta potential obtained in this study was in the range of 13.57-33.87 mV. F2, F5, F7 and F8 showed higher zeta potential values than F1, F3, F4 and F6.

Table 4. Physical characteristics of emulsion formulations.

\begin{tabular}{|c|c|c|c|c|c|}
\hline Formulation & Particle Size (nm) & Polydispersity Index (PdI) & Viscosity (cP) & Surface Tension $(\mathrm{mN} / \mathrm{m})$ & Zeta Potential (mV) \\
\hline F1 & $182.37 C^{z}$ & $0.45 b_{c d}{ }^{z}$ & $4.30 \mathrm{bc}^{\mathrm{z}}$ & $29.18 \mathrm{~d}^{\mathrm{z}}$ & $-26.83 b^{z}$ \\
\hline $\mathrm{F} 2$ & $977.27 a$ & $0.07 \mathrm{e}$ & $4.38 \mathrm{bc}$ & $26.24 \mathrm{f}$ & $-32.70 a$ \\
\hline F3 & $188.07 \mathrm{C}$ & $0.49 \mathrm{bc}$ & $4.32 \mathrm{bc}$ & $29.20 \mathrm{~d}$ & $-16.43 \mathrm{~d}$ \\
\hline $\mathrm{F} 4$ & $171.13 \mathrm{c}$ & $0.51 b$ & $4.49 \mathrm{~b}$ & $25.62 \mathrm{~g}$ & $-22.80 \mathrm{c}$ \\
\hline F5 & $66.44 \mathrm{e}$ & $0.41 \mathrm{~d}$ & $4.20 c$ & $27.62 \mathrm{C}$ & $-32.70 a$ \\
\hline F6 & $899.37 b$ & $0.51 \mathrm{~b}$ & $4.23 \mathrm{bc}$ & $29.52 b$ & $-13.57 \mathrm{~d}$ \\
\hline F7 & $139.63 d$ & $0.40 \mathrm{~cd}$ & $4.37 \mathrm{bc}$ & $26.41 \mathrm{e}$ & $-31.70 a$ \\
\hline F8 & $45.77 \mathrm{e}$ & $0.91 \mathrm{a}$ & $7.50 \mathrm{a}$ & $29.85 a$ & $-33.87 a$ \\
\hline
\end{tabular}

${ }^{\mathrm{z}}$ Means with the same letters within a column are not significantly different at $p>0.05$ using the least significant difference (LSD) test.

3.6. In Situ Antifungal Activity of V. amygdalina-derived Nanoemulsion Formulations Against B. cinerea on Tomato

Based on the formulation characteristics, F5 and F7 showed the best criteria. Thus, both nanoformulations were used for in situ efficacy test against $B$. cinerea in tomato. Refer to Figure 6A, F5 indicated the absence of $B$. cinerea incidence in tomato fruits after 12 days of ambient storage. However, at the same period of storage, the tomato fruits treated with F7 could reduce $95 \%$ and $62.5 \%$ of gray mold disease incidence compared with the negative control and benomyl treated fruits, respectively. Tomato fruits treated with F7 nanoemulsion expressed $1.07 \%$ of disease severity index after 12 days of ambient storage, while that of benomyl fruits expressed less than 15\% (Figure 6B).

The infected areas of these two fruit treatments were covered with slight necrotic and water-soaked lesions (Figure 7). Nevertheless, the lesions were classified on a scale 1 as a mild infection. The fruits treated with F5 nanoemulsion were observed with no gray mold symptoms after 12 days of ambient storage. Negative control fruits showed more than $85 \%$ of gray mold severity on scale 4 that exhibited very severe symptoms of necrotic tissue.

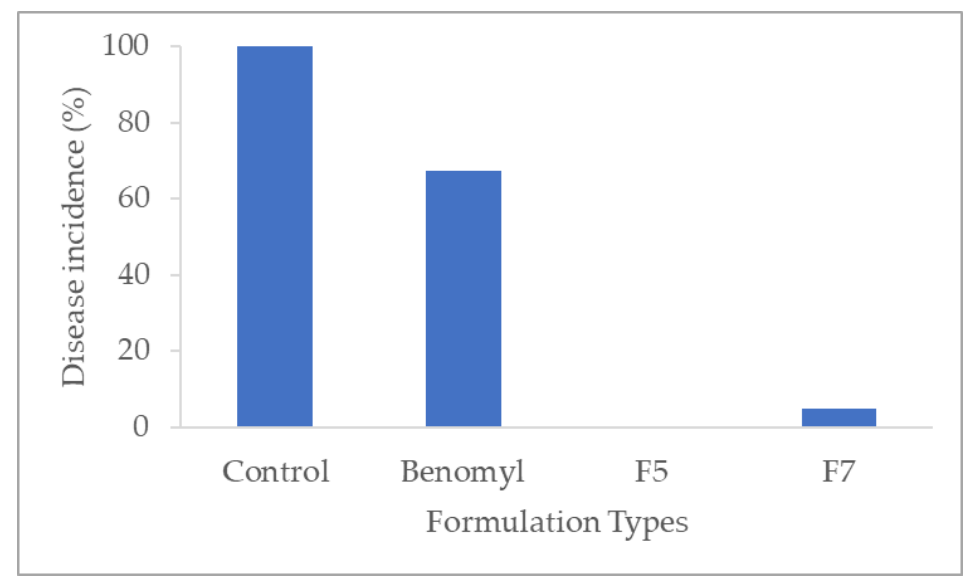

(A)

Figure 6. Cont. 


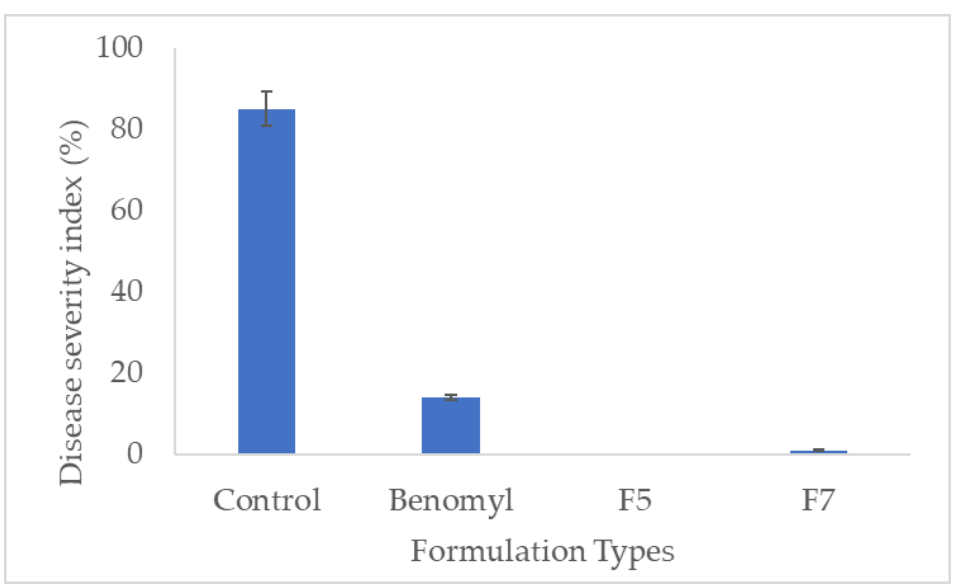

(B)

Figure 6. Effect of formulations types on gray mold. (A) Disease incidence and (B) disease severity index in tomato fruits after 12 days of storage.

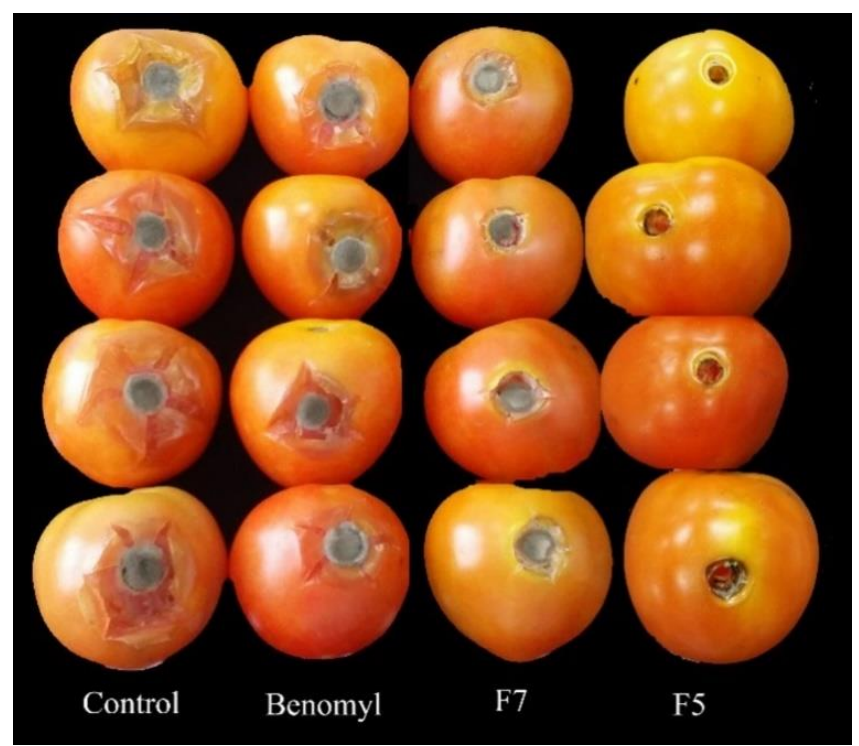

Figure 7. Effect of formulation types on gray mold of tomato fruits.

\section{Discussion}

Kumar et al. [26] stated that the competitive market could be sustained if the nano formulation of pesticides could offer convincing, such as maximized efficiency and durability, good dispersion and biodegradability in the soil and environment. Kah and Hofmann [27] suggested that the active ingredient should also be used in optimum dosage for them to be employed effectively and protect crops from targeted pests and diseases. In pesticide categories, nanoemulsion formulation is the primary selected type among researchers to incorporate with the active compound from the extracted plant because of their miscibility, optimum dispersion stability and efficiency [28].

The ternary phase diagram is a very useful tool for determining the phase behavior of nanoemulsion formulation consisting alkylpolyglucoside surfactant (Glucopon 225, Glucopon 215, Agnique MBL510 and Agnique MBL530), dimethyl amide oil carrier (Agnique AMD810) and water system. Unlike the commercial cationic surfactant that exerts very corrosive and extremely toxic effects on organisms, the non-ionic surfactant alkylpolyglucoside from carbohydrate-based sources is more ecofriendly because it is easily decomposed and is non-toxic to the environment [29]. Haron [8] and Asib et al. [21] found that the mixture surfactants of 50\% Agnique MBL510 and 50\% Agnique MBL530 produced a 4\% wider homogenous isotropic emulsion region in the system compared with the single use 
of Agnique MBL510 surfactant. Contrary to the results of the present study, the equal ratio mixture of Agnique MBL510 and Agnique MBL530 formed an 11\% lower isotropic emulsion region than the Agnique MBL510 surfactant. The difference in findings may be related to the surfactant condition, storage temperature and preparation method of the emulsion system. Glucopon 225 and Glucopon 215 showed poor miscibility in the oil carrier of Agnique AMD810 and resulted in narrow isotropic region with their boundary of not more than $12 \%$ of Agnique AMD810. Within surfactants, only Agnique MBL510 was compatible in the oil component with $38 \%$ maximum miscibility. Agnique AMD810 is a biodegradable and versatile solvent for the formulation of pesticides and is a safe alternative to conventional solvents [30]. Remarkably, all surfactants used in this study were very hydrophilic because their water miscibility reached $93-100 \%$. These criteria were crucial in fabricating a new emulsion formulation because the emulsion type is commonly designed to be mixed with water before use.

In accordance with formulation development, the point selection of surfactant composition did not exceed $18 \%$. The minimal usage of surfactant could minimize the production cost. Surfactants stabilized the emulsion system [31,32], but the excessive amount of surfactant interrupted the delivery of the entrapped bioactive substance [33]. Besides, over-used surfactant causes detrimental effects on biodiversity, because each organism has different sensitivity effects towards surfactant toxicity [34].

Emulsions are thermodynamically unstable systems and possibly form separate layers of oil and water [35]. Stability and thermostability are the main requirements for the development of a novel emulsion formulation to register a new biopesticide, as stated in the Pesticide Board, Malaysia and FAO guidelines. Emulsion stability is defined as the ability of the emulsion to maintain its properties and remain mixed together in a singlephase [36]. In the present study, the centrifugation test and storage stability remained intact in all emulsion formulations at room temperature for four weeks and four months, respectively. However, the thermostability test revealed only F5, F6, F7 and F8 yielded remarkable results. The remaining formulations exhibited flocculation and coalescence. According to Singh et al. [37], thermodynamic stability is vital to ensure that the integrity of droplets remains strong in any temperature fluctuation. Thermodynamic instability may lead to flocculation and coalescence. Flocculation occurs when droplets clump together to form aggregate or flocs without rupturing stabilizing layer at the interface [38]. Flocculation may lead to creaming or sedimentation. This separated layer emulsion was formed with a droplet-rich cream part and a droplet depleted watery part. Payet and Terentjev [39] stated that droplet flocculation occurs because of gravitational force, centrifugation and Brownian forces, where the repulsive energy is less than van der Waals energy. Creaming is a precursor of coalescence. Coalescence occurs when a few droplets merge or fuse together and create a larger droplet [40]. Over time, this condition increased the average droplet size, reduced emulsion stability and resulted in phase separation. This phenomenon is known as Ostwald ripening and is commonly observed in water-in-oil emulsions, where oil molecules diffuse through the aqueous phase and join larger oil droplets [41]. These destabilization phenomena occurred because of several factors, such as the nature and concentration of emulsifier, temperature variation, $\mathrm{pH}$ of the system, ionic strength, homogenization parameters and interaction of dispersed phase with continuous phase [42,43].

In terms of physical characteristics, the best nanoemulsion had a droplet size range of 50-200 nm, high zeta potential charge, low polydispersity index, low viscosity and low surface tension $[4,44,45]$. The present study found that F5, F7 and F8 formulations, which survived in thermostability test, were classified as nanoemulsion because their average droplet size is less than $200 \mathrm{~nm}$. The nanodroplet consists of high proportion of atom on the surface that provides a high-reactivity process of adsorption compared with the macroparticle [46]. The emulsion in nano size also offers a significant advantage in crop protection because it achieves precise and targeted delivery of active ingredients [47]. In terms of particle size distribution, $\mathrm{PdI}$ is used as a parameter to define the size range of the lipidic nanocarrier in emulsion systems. The term polydispersity or dispersity 
as recommended by IUPAC is used to describe the degree of non-uniformity of size distribution of particles [48,49]. Baboota et al. [50] classified that PdI ranges from 0 to 1 , where 0 stands for monodisperse system, and 1 stands for polydisperse particle dispersion. In the present study, F2 had the lowest PdI and categorized as a monodisperse system. Conversely, the thermostable formulations of F5, F6 and F7 had low PdI (closer to 0), and according to Smole et al. [51], this lower range indicates good emulsion homogeneity. Nevertheless, the thermostable formulation of F8 has a very high PdI or heterogeneity index that is prone to Ostwald ripening, leading to nanoemulsion instability. Tadros [52] stated that small particles with a high curvature radius are more soluble than the larger particles. In this case, small particles susceptible to dissolve and diffuse in bulk and deposit on the large particles. After prolonged storage, the droplet size distribution shifts to large sizes, and the transparency of nanoemulsion becomes turbid [53].

Fungicide application is commonly associated with the mixing and pumping of the formula. Thus, the nanoemulsion formula should have low viscosity to ease the application method. Overall, thermostable formulations have generally low viscosity, except F8. Dasgupta and Ranjan [54] stated that small droplet emulsions tend to have high viscosity even at low oil concentration, especially in nanoemulsion. In line with this finding, F8 nanoemulsion had the lowest average of nanodroplet and a lower concentration of Antique AMD810 oil. The efficient emulsion had a low molecule surface tension to adsorbed interface quickly. Tadros [55] reported that the adhesion of emulsion was 100\% when the surface tension decreased to $39 \mathrm{mN} / \mathrm{m}$, whereas only $4 \%$ adhesion occurred when the surface tension was $57 \mathrm{mN} / \mathrm{m}$. In general, the surface tension of the emulsion formulation in the present study was low. Tadros [52] stated that the low surface tension of nanoemulsion is useful for the enhancement of wetting, spreading and penetration of the nanocarrier emulsion to the targeted pathogen. Haron [8] studies found that surface tension at low values of pesticide emulsion allowed the droplets to penetrate and spread evenly on the fruit surface with a small contact angle during application.

Zeta potential is an indicator of the degree of repulsion between the charged droplets in dispersion, and it indirectly denotes the stability of colloidal dispersion [56]. The positive or negative sign indicates the charge present at the particle surface. Previous literature categorized the zeta potential values of $\pm 0-10, \pm 11-20, \pm 21-30$ and more than $\pm 30 \mathrm{mV}$ as highly unstable, relatively stable, moderately stable and highly stable, respectively $[57,58]$. This guideline was used in the present study to classify the stability of the emulsion system based on the zeta potential value. Results demonstrated that the F2, F5, F7 and F8 formulations had the highest reading (over $-30 \mathrm{mV}$ ) of negative zeta potential and were highly stable. F1 and F4 showed significantly lower zeta potential than F2, F5, F7 and F8, but they were still classified as highly stable. F3 and F6 formulations had moderately stable zeta potential. Silva et al. [56] reported that a zeta potential of more than $\pm 30 \mathrm{mV}$ has high resistance towards particle aggregation. The negative charge obtained in the present study is related to the surfactant used. Parallel to this point, Ahmed et al. [59] justified that the emulsion droplets stabilized by non-ionic surfactants would develop a negative charge because of the presence of free fatty acids. The results also agree with those of Chuacharoen et al. [60], in which with the increase in surfactant concentration, the charges of nanoemulsion become more negative and stable.

In situ efficacy supports that F5 nanoemulsion on tomato fruits had a fungicidal effect against $B$. cinerea, causing gray mold disease. No visible gray mold disease symptoms and simultaneous absence in disease severity on tomato fruits were observed during the 12 days of storage. Meanwhile, the application of F7 nanoemulsion caused 5\% disease incidence with $1.07 \%$ disease severity index. Both nanoemulsions contained DVLE as an active component had strong antifungal effects against gray mold disease in tomato compared with synthetic benomyl fungicide. According to Yusoff et al. [17], gas chromatographymass spectrometry (GC-MS) analysis identified 23 chemical compounds in DVLE. The top five major compounds were dominated by squalene $(16.92 \%)$, phytol $(15.05 \%)$, triacontane $(11.31 \%)$, heptacosane $(7.14 \%)$ and neophytadiene $(6.28 \%)$. Some chemical constituents 
such as terpenoid, steroid and fatty acid appeared in lower amounts in this extract. They also found that major and minor antifungal compounds' composition acted as synergistic effects in controlling B. cinerea development.

In our previous study, the mechanism action of the V. amygdalina extract's antifungal compounds on the fungal inhibition was observed under scanning electron microscope [17]. The hyphae of B. cinerea exposed to $V$. amygdalina extract's phytochemical compounds became twisted and folded with a jagged edge. Some mycelia were agglutinated, with withered hyphae tips. Another significant observation was the shrinkage of conidia after the treatment. This mode of action was called antibiosis, which allowed the secondary metabolites from the plant extract to inhibit or restrict the pathogen's growth. Based on this evidence, the active substance of DVLE in the formulation plays a prominent role as an antifungal agent. Meanwhile, the carrier of Agnique AMD810 serves as a medium for conveying the active ingredient to the targeted pathogen.

\section{Conclusions}

This study executed nanoemulsion formulations derived from $V$. amygdalina leaf extract as the main active ingredient with ecofriendly inert ingredients. Among the eight selected formulations, two formulations, F5 and F7 showed the best characteristics and phase behavior. In terms of composition, F5 consists of 18\% Agnique MBL530, 6\% Agnique AMD810 and 36\% water. Meanwhile F7 consists of 12\% Agnique MBL510, $6 \%$ Agnique AMD810 and $42 \%$ water. Both nanoemulsion formulations exhibited thermodynamic stability in storage, the small droplet size of less than $150 \mathrm{~nm}$, low PdI, fair viscosity, low surface tension and high stability according to the zeta potential value. However, through the in situ antifungal activity efficacy test, the F5 nanoemulsion showed the strongest antifungal activity with zero disease incidence and disease severity compared with the F7 nanoemulsion. Based on these findings, the F5 nanoemulsion could be an alternative for harmful synthetic pesticides. However, further studies need to be carried out to evaluate their effect on the postharvest physicochemical quality of tomato to optimize the quality of treated fruits.

Author Contributions: Conceptualization, S.F.Y., M.T.M.M., S.I.I.; methodology, S.F.Y., F.F.H., N.A., and S.I.I.; software, S.F.Y.; validation, S.F.Y., S.I.I., F.F.H. and N.A.; formal analysis, S.F.Y.; investigation, S.F.Y.; resources, F.F.H.; data curation, S.F.Y. and S.I.I.; writing-original draft preparation, S.F.Y.; writing-review and editing, S.F.Y., F.F.H., N.A. and S.I.I.; visualization, S.F.Y.; supervision, S.I.I.; project administration, S.I.I.; funding acquisition, S.I.I. All authors have read and agreed to the published version of the manuscript.

Funding: This research was supported by Ministry of Higher Education (MoHE), Malaysia through Fundamental Research Grant Scheme (FRGS/1/2015/WAB01/UPM/02/5).

Institutional Review Board Statement: Not applicable.

Informed Consent Statement: Not applicable.

Data Availability Statement: The data are available in this article.

Acknowledgments: The authors gratefully acknowledge Skim Latihan Akademik Bumiputera (SLAB) of Malaysia Ministry of Higher Education and Universiti Pendidikan Sultan Idris (UPSI) for scholarship, Zahir Shah Safari for technical work, as well as Malaysian Agricultural Research and Development Institute (MARDI) for research facilities.

Conflicts of Interest: The authors declare no conflict of interest. The funder had no role in the design of the study; in the collection, analyses, or interpretation of data; in the writing of the manuscript, or in the decision to publish the results. 


\section{References}

1. Abbey, J.A.; Percival, D.; Abbey, L.; Asiedu, S.K.; Prithiviraj, B.; Schilder, A. Biofungicides as alternative to synthetic fungicide control of grey mould (Botrytis cinerea)—Prospects and challenges. Biocontrol Sci. Technol. 2019, 29, 207-228. [CrossRef]

2. Zhao, S.; Guo, Y.; Wang, Q.; Luo, H.; He, C.; An, B. Expression of flagellin at yeast surface increases biocontrol efficiency of yeast cells against postharvest disease of tomato caused by Botrytis cinerea. Postharvest Biol. Technol. 2020, 162, 111112. [CrossRef]

3. Zaker, M. Natural Plant Products as Eco-friendly Fungicides for Plant Diseases Control—A Review. Agriculture 2016, 14, 134-141. [CrossRef]

4. $\quad$ Borges, D.F.; Lopes, E.A.; Moraes, A.R.F.; Soares, M.S.; Visôtto, L.E.; Oliveira, C.R.; Valente, V.M.M. Formulation of botanicals for the control of plant-pathogens: A review. Crop. Prot. 2018, 110, 135-140. [CrossRef]

5. Miresmailli, S.; Isman, M.B. Botanical insecticides inspired by plant-herbivore chemical interactions. Trends Plant Sci. 2014, 19, 29-35. [CrossRef]

6. Benelli, G.; Pavela, R.; Maggi, F.; Petrelli, R.; Nicoletti, M. Commentary: Making Green Pesticides Greener? The Potential of Plant Products for Nanosynthesis and Pest Control. J. Clust. Sci. 2016, 28, 3-10. [CrossRef]

7. Rashid, T.S. Antimicrobial Activity of Rhus coriaria L. Fruit Extracts Against Selected Bacterial and Fungal Pathogens on Tomato. Ph.D. Thesis, University Putra Malaysia, Selangor, Malaysia, 12 May 2016.

8. Haron, F.F. Antifungal Activity of Allamanda Spp. Extracts and Their Microemulsion Formulations Against Anthracnose (Colletotrichum Gloeosporioides) Disease of Papaya. Ph.D. Thesis, University Putra Malaysia, Selangor, Malaysia, October 2012.

9. Pant, M.; Dubey, S.; Patanjali, P.K. Recent Advancements in Bio-Botanical Pesticide Formulation Technology Development. In Herbal Insecticides, Repellents and Biomedicines: Effectiveness and Commercialization; Vijay, V., Gopalakrishnan, R., Eds.; Springer International Publishing: New Delhi, India, 2016; pp. 117-126.

10. Sharma, R.; Kumari, A.; Singh, N.S.; Singh, M.K.; Dubey, S.; Iqbal, N.; Patanjali, P.K. Development and stability enhancement of neem oil based microemulsion formulation using botanical synergist. J. Mol. Liq. 2019, 296, 112012. [CrossRef]

11. Campos, E.V.; Proença, P.L.; Oliveira, J.L.; Bakshi, M.; Abhilash, P.; Fraceto, L.F. Use of botanical insecticides for sustainable agriculture: Future perspectives. Ecol. Indic. 2019, 105, 483-495. [CrossRef]

12. Kookana, R.S.; Boxall, A.B.A.; Reeves, P.T.; Ashauer, R.; Beulke, S.; Chaudhry, Q.; Cornelis, G.; Fernandes, T.F.; Gan, J.; Kah, M.; et al. Nanopesticides: Guiding Principles for Regulatory Evaluation of Environmental Risks. J. Agric. Food Chem. 2014, 62, 4227-4240. [CrossRef]

13. Anton, N.; Vandamme, T.F. Nano-emulsions and Micro-emulsions: Clarifications of the Critical Differences. Pharm. Res. 2010, 28, 978-985. [CrossRef]

14. Aboofazeli, R. Nanometric-scaled emulsions (nano-emulsions). Iran. J. Pharm. Res. 2010, 9, 325-326.

15. Taylor, P. Ostwald ripening in emulsions. Adv. Colloid Interface Sci. 1998, 75, 107-163. [CrossRef]

16. Kale, S.N.; Deore, S.L. Emulsion Micro Emulsion and Nano Emulsion: A Review. Syst. Rev. Pharm. 2016, 8, 39-47. [CrossRef]

17. Yusoff, S.F.; Haron, F.F.; Mohamed, M.T.M.; Asib, N.; Sakimin, S.Z.; Abu Kassim, F.; Ismail, S.I. Antifungal Activity and Phytochemical Screening of Vernonia amygdalina Extract against Botrytis cinerea Causing Gray Mold Disease on Tomato Fruits. Biology 2020, 9, 286. [CrossRef]

18. Siti Fairuz, Y.; Ismail, S.I.; Farah Farhanah, H.; Mahmud, T.M.M. Phytochemical Composition in Hexane and Methanolic Leaf Extract of Vernonia amygdalina. Malays. Appl. Biol. 2019, 48, 11-17.

19. Rahmani, M.; Haron, F.F.; Sijam, K.; Omar, D. Bioassay-guided Isolation of Antifungal Plumericin from Allamanda Species (Apocynaceae). J. Biol. Sci. 2013, 13, 158-162. [CrossRef]

20. Choupanian, M.M.C.; Omar, D.D.O.; Basri, M.M.B.; Asib, N.N.A. Preparation and characterization of neem oil nanoemulsion formulations against Sitophilus oryzae and Tribolium castaneum adults. J. Pestic. Sci. 2017, 42, 158-165. [CrossRef] [PubMed]

21. Asib, N.; Omar, D.; Awang, R.M.; Ashikin, N.; Abdullah, P. Preparation, characterization and toxicity of nano-emulsion formulations of rotenone extract of Derris Elliptica. J. Chem. Biol. Phys. Sci. 2015, 5, 3989-3997.

22. Department of Agriculture (DoA). Maklumat Racun Perosak. Available online: http://www.doa.gov.my/index/resources/ aktiviti_sumber/sumber_awam/maklumat_racun_perosak/slaid/slaid3.pdf (accessed on 17 November 2020).

23. World Health Organization and Food Agricultural Organization. Manual on Development and Use of FAO and WHO Specifications for Pesticides, 1st ed.; WHO Press: Rome, Italy, 2016; 144p.

24. Rosero-Hernández, E.D.; Moraga, J.; Collado, I.G.; Echeverri, F. Natural Compounds That Modulate the Development of the Fungus Botrytis cinerea and Protect Solanum lycopersicum. Plants 2019, 8, 111. [CrossRef] [PubMed]

25. Benita, S. Microencapsulation: Methods and Industrial Applications, 2nd ed.; CRC Press: New York, NY, USA, 2005; 355p.

26. Kumar, S.; Nehra, M.; Dilbaghi, N.; Marrazza, G.; Hassan, A.A.; Kim, K.-H. Nano-based smart pesticide formulations: Emerging opportunities for agriculture. J. Control. Release 2019, 294, 131-153. [CrossRef] [PubMed]

27. Kah, M.; Hofmann, T. Nanopesticide research: Current trends and future priorities. Environ. Int. 2014, 63, 224-235. [CrossRef]

28. Chandrasekaran, N.; Sugumar, S.; Mukherjee, A. Nanoemulsion formation and characterization by spontaneous emulsification: Investigation of its antibacterial effects on Listeria monocytogenes. Asian J. Pharm. 2015, 9, 23. [CrossRef]

29. Jiang, L.C.; Basri, M.; Omar, D.; Rahman, M.B.A.; Salleh, A.B.; Rahman, R.N.Z.R.A.; Selamat, A. Green nano-emulsion intervention for water-soluble glyphosate isopropylamine (IPA) formulations in controlling Eleusine indica (E. indica). Pestic. Biochem. Physiol. 2012, 102, 19-29. [CrossRef] 
30. Kamarudin, N. Oil Nano-emulsion Formulation of Azadirachtin for Control of Bemisia Tabaci Gennadius. Ph.D. Thesis, University Putra Malaysia, Selangor, Malaysia, July 2013.

31. Zheng, L.; Cao, C.; Chen, Z.; Cao, L.; Huang, Q.; Song, B. Evaluation of emulsion stability by monitoring the interaction between droplets. LWT 2020, 132, 109804. [CrossRef]

32. Costa, C.; Medronho, B.; Filipe, A.; Mira, I.; Lindman, B.; Edlund, H.; Norgren, M. Emulsion Formation and Stabilization by Biomolecules: The Leading Role of Cellulose. Polymers 2019, 11, 1570. [CrossRef]

33. Barzegar, A.; Moosavi-Movahedi, A.A. Intracellular ROS Protection Efficiency and Free Radical-Scavenging Activity of Curcumin. PLoS ONE 2011, 6, e26012. [CrossRef] [PubMed]

34. Lechuga, M.; Fernández-Serrano, M.; Jurado, E.; Núñez-Olea, J.; Ríos, F. Acute toxicity of anionic and non-ionic surfactants to aquatic organisms. Ecotoxicol. Environ. Saf. 2016, 125, 1-8. [CrossRef]

35. Agarwal, S.P.; Rajesh, K. Physical Pharmacy, 2nd ed.; CBS Publisher: Delhi, India, 2007; pp. 177-186.

36. Maphosa, Y.; Jideani, V.A.; Adeyi, O. Effect of soluble dietary fibres from Bambara groundnut varieties on the stability of orange oil beverage emulsion. Afr. J. Sci. Technol. Innov. Dev. 2017, 9, 69-76. [CrossRef]

37. Singh, Y.; Meher, J.G.; Raval, K.; Khan, F.A.; Chaurasia, M.; Jain, N.K.; Chourasia, M.K. Nanoemulsion: Concepts, development and applications in drug delivery. J. Control. Release 2017, 252, 28-49. [CrossRef] [PubMed]

38. Mao, L.; Miao, S. Structuring Food Emulsions to Improve Nutrient Delivery During Digestion. Food Eng. Rev. 2015, 7, 439-451. [CrossRef]

39. Payet, L.; Terentjev, E.M. Emulsification and Stabilization Mechanisms of O/W Emulsions in the Presence of Chitosan. Langmuir 2008, 24, 12247-12252. [CrossRef]

40. Chanamai, R.; McClements, D.J. Impact of Weighting Agents and Sucrose on Gravitational Separation of Beverage Emulsions. J. Agric. Food Chem. 2000, 48, 5561-5565. [CrossRef]

41. Jiao, J.; Burgess, D.J. Ostwald ripening of water-in-hydrocarbon emulsions. J. Colloid Interface Sci. 2003, 264, 509-516. [CrossRef]

42. McClements, D.J. Food Emulsions: Principles, Practices, and Techniques, 3rd ed.; CRC Press: New York, NY, USA, 2015; pp. 289-373.

43. Sjöblom, J.; Stenius, P.; Simon, S.; Grimes, B.A. Emulsion Stabilization. In Encyclopedia of Colloid and Interface Science, 1st ed.; Tadros, T., Ed.; Springer International Publishing: Heidelberg, Germany, 2013; pp. 415-454.

44. Gurpret, K.; Singh, S.K. Review of Nanoemulsion Formulation and Characterization Techniques. Indian J. Pharm. Sci. 2018, 80, 781-789. [CrossRef]

45. Da Costa, S.; Basri, M.; Shamsudin, N.; Basri, H. Stability of Positively Charged Nanoemulsion Formulation Containing Steroidal Drug for Effective Transdermal Application. J. Chem. 2014, 2014, 1-8. [CrossRef]

46. Zhang, T.; Murphy, M.J.; Yu, H.; Bagaria, H.G.; Yoon, K.Y.; Neilson, B.M.; Bielawski, C.W.; Johnston, K.P.; Huh, C.; Bryant, S.L. Investigation of Nanoparticle Adsorption During Transport in Porous Media. SPE J. 2015, 20, 667-677. [CrossRef]

47. Glare, T.; Caradus, J.; Gelernter, W.; Jackson, T.; Keyhani, N.; Köhl, J.; Marrone, P.; Morin, L.; Stewart, A. Have biopesticides come of age? Trends Biotechnol. 2012, 30, 250-258. [CrossRef] [PubMed]

48. Bera, B. Nanoporous silicon prepared by vapour phase strain etch and sacrificial technique. Int. J. Comput. Appl. 2015, $975,8887$.

49. Nobbmann, U.L. Polydispersity-What Does It Mean for DLS and Chromatography. Available online: http:/ / www.materialstalks.com/blog/2014/10/23/polydispersity-what-does-it-mean-for-dls-and-chromatography (accessed on 18 November 2020).

50. Baboota, S.; Shakeel, F.; Ahuja, A.; Ali, J.; Shafiq, S. Design, development and evaluation of novel nanoemulsion formulations for transdermal potential of celecoxib. Acta Pharm. 2007, 57, 315-332. [CrossRef]

51. Smole, M.S.; Hribernik, S.; Kurečič, M.; Krajnc, A.U.; Kreže, T.; Kleinschek, K.S. Surface Properties of Non-conventional Cellulose Fibres, 1st ed.; Springer International Publishing: Cham, Switzerland, 2019; 85p.

52. Tadros, T. Ostwald Ripening. In Encyclopedia of Colloid and Interface Science, 1st ed.; Tadros, T., Ed.; Springer International Publishing: Heidelberg, Germany, 2013; 820p.

53. Sharma, N.; Bansal, M.; Visht, S.; Sharma, P.K.; Kulkarni, G.T. Nanoemulsion: A new concept of delivery system. Chron. Young Sci. 2010, 1, 2 .

54. Dasgupta, N.; Ranjan, S. Nanoemulsion in Food. In An Introduction to Food Grade Nano-Emulsions; Dasgupta, N., Ranjan, S., Eds.; Springer: Singapore, 2018; Volume 13, 35p.

55. Tadros, T.F. Agrochemicals, Paints and Coatings and Food Colloids. In Formulation Science and Technology, 1st ed.; Tadros, T.F., Ed.; Deutsche Nationalbibliothek: Berlin, Germany, 2018; Volume 4, pp. 245-254.

56. Silva, H.D.; Cerqueira, M.; Vicente, A.A. Nanoemulsions for Food Applications: Development and Characterization. Food Bioprocess Technol. 2012, 5, 854-867. [CrossRef]

57. Sepúlveda-Rivas, S.; Fritz, H.F.; Valenzuela, C.; Santiviago, C.A.; Morales, J.O. Development of Novel EE/Alginate Polyelectrolyte Complex Nanoparticles for Lysozyme Delivery: Physicochemical Properties and In Vitro Safety. Pharm. 2019, 11, 103. [CrossRef]

58. Bhattacharjee, S. DLS and zeta potential—What they are and what they are not? J. Control. Release 2016, 235, 337-351. [CrossRef]

59. Ahmed, K.; Li, Y.; McClements, D.J.; Xiao, H. Nanoemulsion- and emulsion-based delivery systems for curcumin: Encapsulation and release properties. Food Chem. 2012, 132, 799-807. [CrossRef]

60. Chuacharoen, T.; Prasongsuk, S.; Sabliov, C.M. Effect of Surfactant Concentrations on Physicochemical Properties and Functionality of Curcumin Nanoemulsions Under Conditions Relevant to Commercial Utilization. Molecules 2019, 24, 2744. [CrossRef] [PubMed] 